University of Nebraska - Lincoln

DigitalCommons@University of Nebraska - Lincoln

Publications from USDA-ARS / UNL Faculty

U.S. Department of Agriculture: Agricultural

Research Service, Lincoln, Nebraska

1998

\title{
Yield and stability factors associated with hybrid wheat
}

R. Bruns

Agripro Seeds Inc.

C. J. Peterson

USDA-ARS

Follow this and additional works at: https://digitalcommons.unl.edu/usdaarsfacpub

Part of the Agricultural Science Commons

Bruns, R. and Peterson, C. J., "Yield and stability factors associated with hybrid wheat" (1998).

Publications from USDA-ARS / UNL Faculty. 234.

https://digitalcommons.unl.edu/usdaarsfacpub/234

This Article is brought to you for free and open access by the U.S. Department of Agriculture: Agricultural Research Service, Lincoln, Nebraska at DigitalCommons@University of Nebraska - Lincoln. It has been accepted for inclusion in Publications from USDA-ARS / UNL Faculty by an authorized administrator of DigitalCommons@University of Nebraska - Lincoln. 


\title{
Y ield and stability factors associated with hybrid wheat
}

\author{
R. Bruns ${ }^{1} \&$ C. J. Peterson ${ }^{2}$ \\ ${ }^{1}$ A gripro Seeds Inc., P.O. B ox 30, B erthoud, C O , 80513, U.S.A .; ${ }^{2}$ U SDA -A R S U niversity of N ebraska, L incoln, \\ NE , 68583, U.S.A.
}

\section{Summary}

For hybrid wheat to be accepted in the G reat Plains of the U SA , hybrids must exhibit enhanced yield performance, yield responsiveness, and reasonable yield stability across a wide array of production environments. A gripro has been researching hybrid wheat since 1981 and has an established pureline release history since 1978. Y ield data from 1991 to 1995 were examined to compare the trend performance and selection gains of purelines and hybrids in a large scale parallel development effort. This data set (13,739 points) reveals an average $0.454 \mathrm{t} \mathrm{ha}^{-1}$ or $10.8 \%$ hybrid yield advantage over purelines in preliminary regional testing. E ntries selected from the preliminary trials show a greater hybrid advantage of $0.652 \mathrm{t} \mathrm{ha}^{-1}$, or $13.5 \%$. Several factors including enhanced stability over strong yearly environmental effects, improved agronomic and epidemiological expression through complementary inbred trait selection, and improved heat tolerance are likely contributors to this significantly improved selection gain. Y ield stability of hybrids and purelines was compared in A gripro Standard Variety Trials and U SDA -A R S Southern R egional Performance N urseries from 1990 to 1995. In addition to having higher means than purelines, hybrid yield advantage increased with improving production conditions. The enhanced responsiveness of hybrids, as indicated by higher slopes in regression analyses, was combined with similar deviations from regression response. $\mathrm{H}$ ybrid wheat in the $\mathrm{G}$ reat $\mathrm{Plains}$ of the U SA has shown a fundamental yield, responsiveness and selection gain advantage over pureline varieties that could result in acceptance by producers.

\section{Introduction}

H ybrid hard winter wheats (Triticum aestivum L .) have shown superior grain yield potential in regional and state performance trials over the last decade, but not at a level that would indicate an obvious economic benefit to growers. N ew information on hybrid yield potential and response to environmental variation is needed to demonstrate economic value and identify target production areas for hybrid wheat in the U S G reat Plains.

Carver et al. (1987) used O klahoma performance trials to show that, although hybrids generally had higher mean yields, hybrid and semidwarf purelines cultivars had generally similar responses to production environments based on regression and cluster analyses. However, since the study by $\mathrm{C}$ arver et al.
(1987), there have been significant advances in hybrid wheat breeding and seed production facilitated by development and use of experimental chemical hybridising agents (M ock, 1995). Compared with cytoplasmic male sterility systems, chemical hybridising agents provide means to generate large numbers of parental combinations, reduce time required for hybrid development, and improve hybrid breeding efficiency.

A gripro Seeds Inc. (A SI) has been in a unique situation to examine yield response of hybrid and pureline hard winter wheats. A SI has been breeding and releasing pureline varieties since 1974 and has had access to chemical hybridising agents since 1981. A SI has used its pureline breeding base to generate large numbers of hybrids that have been evaluated under parallel environments as the pure- 
lines. These factors allow us to examine a large standardised data set comparing grain yields and response to selection of purelines and hybrids.

A number of hybrids have been tested in the $U$ nited States D epartment of A griculture A gricultural R esearch Service (USA DA -A R S) Southern R egional Performance Nursery (SRPN) over the last decade. The SR PN performance data have suggested that hybrids may have improved yield stability and response to favourable environments when grown over a broad array of production conditions. A nalyses of multiple years of data and information from the SR PN and A gripro Standard Variety Trial (SVT), also grown region-wide, could more effectively establish differences in yield performance, yield stability, and responsiveness of hybrids and purelines, should differences exist.

\section{M aterials and methods}

O ver time, A SI has developed a breeding strategy for purelinesand hybrids that included parallel testing of preliminary purelines and preliminary hybrids at nearly the same scale, selection intensity, selection criteria, and yield testing scope. The breeding targets for purelines and hybrids have remained constant at 400-500 new entries of each in preliminary regional testing and 50-60 entries that advance to full scale regional evaluation. This balanced approach to hybrid and pureline testing enables a unique examination of a very large data set comparing purelines and hybrids derived from the same germplasm base.

Y ield data of early generation hybrids and purelines were compared in A gripro preliminary yield trials grown from 1991-1994 and in advanced yield trials grown from 1992-1995. Y ields for all entries were standardised by comparing performance to a standard control (H awk) and include only locations where both purelines and hybrids were evaluated. $D$ ata from the preliminary trials consisted of 12,209 yield measurements (6010 pureline, 6199 hybrid) over 13 common location/years representing 3728 genotypes (1806 pureline, 1922 hybrid). In the following years of advanced trials, data consisted of 1530 yield values ( 796 pureline, 734 hybrid) over 13 common locations/years of tests representing 463 genotypes ( 246 pureline, 217 hybrid). D istributions of hybrid and pureline entry yields were contrasted in the preliminary and advanced trials. D ifferences in gain from selection were estimated by comparing mean yields of hybrids and purelines in the preliminary vs. selected hybrids and purelines in the advanced trials. A nalyses were conducted by comparing the standard error of the differences of the mean of the populations.

A gripro utilises a proprietary computer software program that compares agronomic, pathologic, and quality traits of inbreds and provides a ranking of hybrid candidates prior to yield testing. This program effectively eliminates hybrids that have a critical flaw, and helps promote a higher percentage of hybrids that pyramid disease and pest protection genes. A II hybrids tested are targeted to fall within acceptable agronomic, pathologic, and quality parameters.

Y ield stability and environmental responsiveness of hybrids and purelines were compared using data from the Southern R egional Performance N ursery (SR PN ), from 1990-1995, and A gripro Standard Variety Trial (SV T) in 1993 and 1994. Four to six hybrids were included in the SR PN trials and number of purelinesincluded in analyses ranged from 30-36, as long term checks were excluded. The 1993 SV T included five A gripro hybrids and 20 purelines grown at nine locations in the $G$ reat Plains. The 1994 SV T included 16 A gripro hybrids and 28 purelines grown at 16 locations in the region. E ach year of the SR PN and SV T were analysed separately as entries in the nurseries varied among years.

Pureline and hybrid yields were regressed on an environmental index based on average yield of pureline entries at each location, following the approach of E berhart \& R ussell (1966). By doing so, average pureline regression slope was, by definition, $b=1.0$, and average pureline intercept was at 0.0 tha $^{-1}$. G L M (SA S I nstitute, 1982) was used to test heterogeneity of slopes between hybrids and purelines, and among entries within these two genotypic classes. R egression response of purelines and hybrids were plotted for each year and a 95\% confidence interval was calculated to represent average variances around pureline and hybrid regressions. 
Table 1. Summary of A gripro testing scope and mean yield deviation from control comparisons

\begin{tabular}{|c|c|c|c|c|c|}
\hline Preliminary trials & 1991 & 1992 & 1993 & 1994 & Totals \\
\hline locations & 3 & 3 & 3 & 4 & 13 \\
\hline pureline mean yield t ha-1 & 0.223 & 0.551 & 1.127 & -0.380 & 0.333 \\
\hline hybrid mean yield t ha ${ }^{-1}$ & 0.526 & 1.198 & 1.465 & 0.036 & 0.787 \\
\hline hybrid advantage t ha ${ }^{-1}$ & $0.303^{* *}$ & $0.647^{* *}$ & $0.338 * *$ & $0.416^{* *}$ & $0.454 * *$ \\
\hline$\%$ advantage & $10.0 \%$ & $14.0 \%$ & $7.4 \%$ & $9.6 \%$ & $10.8 \%$ \\
\hline A dvanced trials & 1992 & 1993 & 1994 & 1995 & Totals \\
\hline locations & 3 & 3 & 2 & 5 & 13 \\
\hline pureline mean yield t ha-1 & 0.568 & 0.783 & -0.330 & 0.776 & 0.561 \\
\hline hybrid mean yield t ha ${ }^{-1}$ & 1.136 & 1.579 & -0.120 & 1.377 & 1.213 \\
\hline hybrid advantage t ha-1 & $0.568 * *$ & $0.796 * *$ & $0.210^{*}$ & $0.601 * *$ & $0.652 * *$ \\
\hline$\%$ advantage & $10.6 \%$ & $16.2 \%$ & $2.9 \%$ & $16.3 \%$ & $13.5 \%$ \\
\hline pureline selection gain & $0.345^{* *}$ & $0.232 * *$ & $-1.457^{* *}$ & $1.156^{* *}$ & $0.228 * *$ \\
\hline hybrid selection gain & $0.610 * *$ & $0.381 * *$ & $-1.590 * *$ & $1.341 * *$ & $0.426 * *$ \\
\hline hybrid improved gain & $0.265^{*}$ & 0.149 & -0.133 & $0.185^{* *}$ & $0.198 * *$ \\
\hline
\end{tabular}

$*, * *$ Significantly different from pureline values at the 0.05 and 0.01 probability levels, respectively.

\section{R esults}

A gripro breeding trials demonstrate a hybrid advantage of $0.454 \mathrm{tha}^{-1}$ over purelines in preliminary yield trials, with an average yield level of $4.196 \mathrm{tha}^{-1}$ (Table 1). This represents a $10.8 \%$ average hybrid advantage over four years of regional testing. The yield advantage of hybrids was significant in all four years as well as the four year pool. D etails of testing scale and yield comparisons are illustrated in Table 1 and yield distributions are illustrated in Figure 1 . Since the hybrid and pureline germplasm base are essentially the same, it can be assumed that the average heterosis level in this germplasm set would be approximately $10.8 \%$.

W hen hybrid and pureline selections were tested in advanced trials, there was a hybrid advantage of $0.652 \mathrm{t} \mathrm{ha}^{-1}$, at an average yield level of $4.835 \mathrm{t} \mathrm{ha}^{-1}$. This represents a $13.5 \%$ average hybrid advantage over four years of regional testing. The yield advantage of hybrids was significant in all four years as well as the four year pool. Y ield distributions are illustrated in Figure 2.

The $13.5 \%$ average hybrid advantage of advanced hybrids compared with $10.8 \%$ in the preliminary yield trials over a four year period demonstrates a significant gain-from-selection advantage for hybrids over purelines. Since the genetic base, selection intensity, and selection criteria for the purelines and the hybrids were essentially equal, this selection gain was unexpected.

The SR PN and SV T nurseries provided environments with a wide array of wheat production conditions, with location mean yields of purelines ranging from less than 1.0 to over $9.0 \mathrm{t} \mathrm{ha}^{-1}$. In the SR PN, hybrid mean yields significantly exceeded the pure-

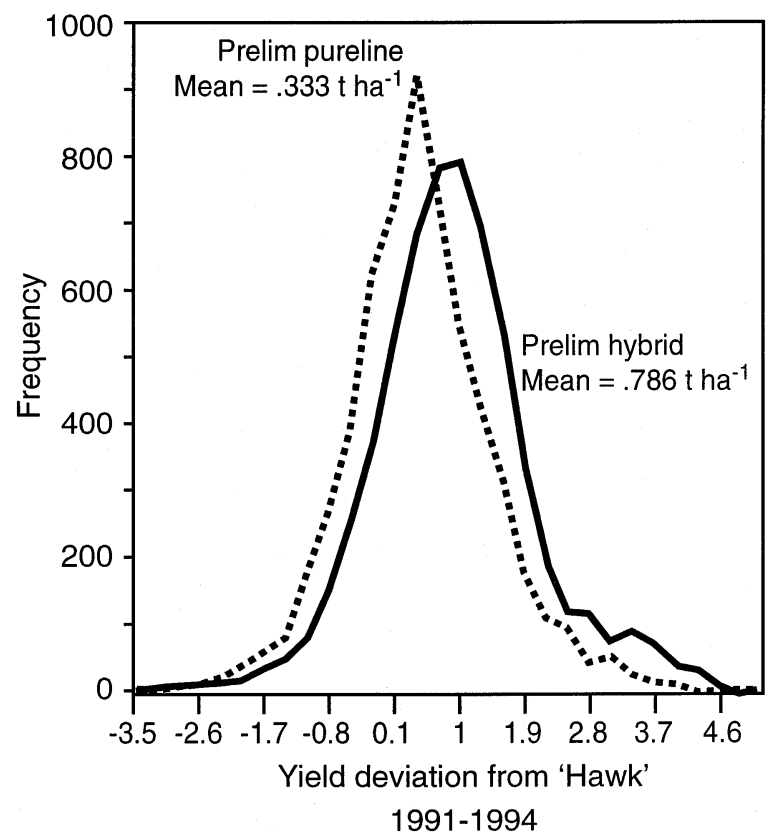

Figure 1. Four-year yield distributions: preliminary pureline vs. preliminary hybrid. 


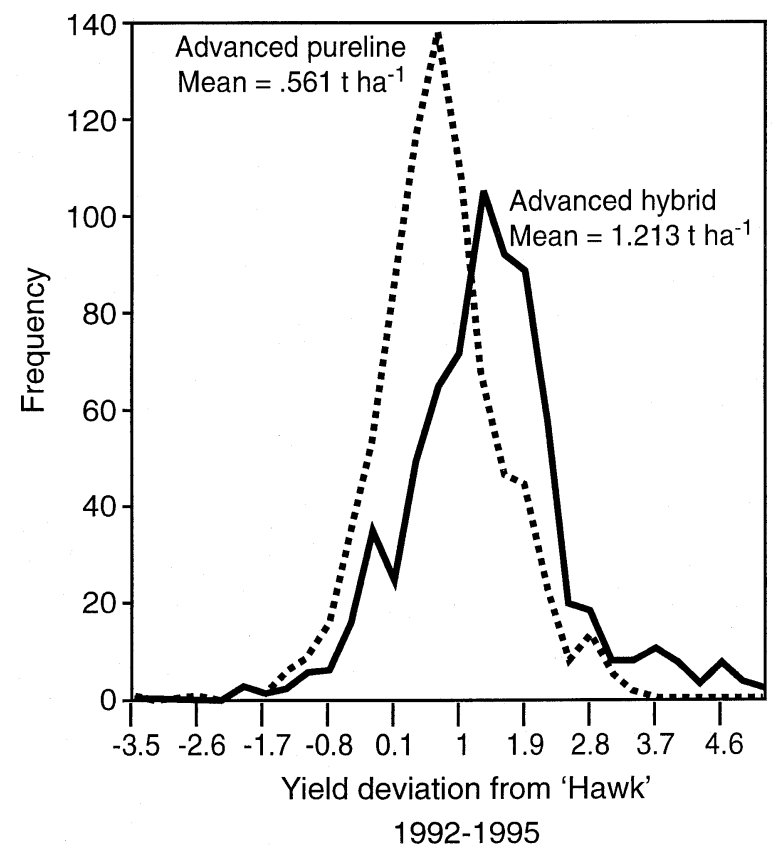

Figure 2. Four-year yield distributions: advanced pureline vs. advanced hybrid.

line means in all but one year, ranging from a $0.22 \mathrm{t}$ $\mathrm{ha}^{-1}-0.46 \mathrm{t} \mathrm{ha}^{-1}$ average yield advantage. In the 1993 and 1994 SV T, average hybrid yields exceeded the yield of pureline cultivars by 0.49 and $0.55 \mathrm{t} \mathrm{ha}^{-1}$, respectively.

R egression response of both hybrid and pureline grain yields was linear in all years. There was significant heterogeneity for slopes among purelines in all but one of the trials. This heterogeneity was not unexpected, as the purelines evaluated in each nursery were of diverse genetic background and origin. A mong hybrids tested, there was significant heterogeneity for regression slope only in the 1990 and 1991 SR PN, indicating that the hybrids had similar environmental responses each year.

$\mathrm{H}$ ybrids and purelines, as genotypic classes, showed significantly different responsesto environmental variation in the SR PN in 1994 and 1995, and SV T in 1993 and 1994. In these trials, hybrid regression slopes ranged from $b=1.09$ to 1.12 compared with $b=1.0$ for purelines. H owever, average hybrid and pureline responses were not statistically different in the 1990-1993 SR PN trials. Pooled deviations from linear regression response, in terms of M S deviations and SE (b), were of similar magnitude for hybrids and purelines in each trial. A s such, there was no evidence that hybrids provided an additional component of yield stability in terms of reduced

Table 2. Linear regression analyses of hybrid and pureline mean yields in the Southern R egional Performance N ursery (SR PN), 19901995, and A gripro Standard Variety Trial (SV T), 1993-1994

\begin{tabular}{|c|c|c|c|c|}
\hline & 1990 SR PN & 1991 SR PN & 1992 SR PN & 1993 SR PN \\
\hline \multicolumn{5}{|l|}{ H ybrids } \\
\hline M ean, t ha-1 & 3.54 & $3.67 \dagger$ & $3.85^{*}$ & $4.78 * *$ \\
\hline Intercept & 0.00 & 0.10 & 0.02 & 0.43 \\
\hline $\mathrm{b}$ & 1.06 & 1.04 & 1.07 & 1.00 \\
\hline SE (b) & 0.05 & 0.04 & 0.02 & 0.05 \\
\hline \multicolumn{5}{|l|}{ Purelinesł } \\
\hline M ean, t ha-1 & 3.34 & 3.45 & 3.58 & 4.38 \\
\hline \multirow[t]{2}{*}{ SE (b) } & 0.06 & 0.05 & 0.06 & 0.06 \\
\hline & 1994 SR PN & 1995 SR PN & 1993 SV T & 1994 SV T \\
\hline \multicolumn{5}{|l|}{ H ybrids } \\
\hline M ean, t ha-1 & $3.64 * *$ & $3.47 * *$ & $4.81^{* *}$ & $4.70 * *$ \\
\hline Intercept & 0.17 & 0.04 & 0.12 & 0.00 \\
\hline $\mathrm{b}$ & $1.09 *$ & $1.10 \dagger$ & $1.10^{*}$ & $1.12^{* *}$ \\
\hline SE (b) & 0.07 & 0.08 & 0.05 & 0.06 \\
\hline \multicolumn{5}{|l|}{ Purelinesł } \\
\hline M ean, t ha-1 & 3.18 & 3.13 & 4.25 & 4.21 \\
\hline SE (b) & 0.07 & 0.07 & 0.06 & 0.05 \\
\hline
\end{tabular}

$\dagger, *, * *$ Significantly different from pureline values at the $0.10,0.05$, and 0.01 probability levels, respectively. $\ddagger$ Intercept and $b$ values for average pureline response are 0.0 and 1.0 , respectively, for each trial. 
deviations from expected response. H owever, there was also no associated increase in deviations, as might have occurred considering the enhanced responsiveness and higher mean yields in the hybrids. $D$ etailed regression analyses of hybrid and pureline mean yield response for the SR PN and SV T is illustrated in Table 2.

There was no crossover between hybrid and pureline regression responses indicated in any of the trials. In the SR PN trials, the $95 \% \mathrm{CI}$ for hybrid and pureline yield responses mostly overlapped. In the 1993 and 1994 SV T, hybrid and pureline confidence intervals overlapped at lower yield levels, but as environmental yield potential exceeded approximately 3.5 t ha $^{-1}$, the hybrid and pureline confidence intervals diverge. This would suggest a high probability for hybrid yields to exceed pureline yields in these more favourable environments.

\section{D iscussion and conclusion}

Multiple year performance trial data comparing purelines and hybrids at both preliminary and advanced stages show strong evidence for substantial hybrid yield advantage, hybrid responsiveness to favourable environments, and similar deviations from regression response. There is a significant improvement of selection efficiency of the hybrid group relative to purelines. The improved selection gain must be attributed to one or a combination of the following factors:

1. Enhanced stability over strong yearly environmental effects is plausible, but has to be tempered by the fact that within year stability deviation from response is essentially equal among hybrids and purelines.
2. Improved agronomic and epidemiological expression through computer assisted complementary inbred trait selection.

3. H eterosis for green leaf duration that is manifested by improved heat tolerance. (Van M eeteren, 1995).

U nderstanding the components of this improved selection gain in $\mathrm{G}$ reat Plains hybrids through targeted experiments is warranted.

With continued development and appropriate hybrid selection strategies, hybrids can provide growers with added value expressed through a high probability of enhanced grain yield and improved yield responsiveness, combined with similar levels of yield stability relative to conventional pureline cultivars. If this added value is greater than hybrid seed production expense, hybrids may be accepted on a wide scale in the G reat Plains of the U SA .

\section{$R$ eferences}

Carver, B.F., E.L. Smith \& H.O. E ngland, J r., 1987. R egression and cluster analysis of environmental responses of hybrid and pureline winter wheat cultivars. Crop Sci 27: 659-664.

E berhart, S.A . \& W.A. R ussell, 1966. Stability parameters for comparing varieties. A gronomy J 6: 36-40.

M ock, J.J., 1995. A new look at hybrid wheat and its role in improving yield and quality. In: C.J. Peterson (E d.), Proceedings of the North A merican Wheat Workers Workshop, 1994, pp. 20-34. National Wheat Improvement Committee. Kansas City.

SA S Institute, 1982. SA S user's guide: Statistics. SA S Institute Inc., Cary, NC.

Van M eeteren, N.D , 1995. H ybrid and pureline response to high temperature stress at two growth stages in hard red winter wheat. A gronomy A bstracts 87: 80 . 